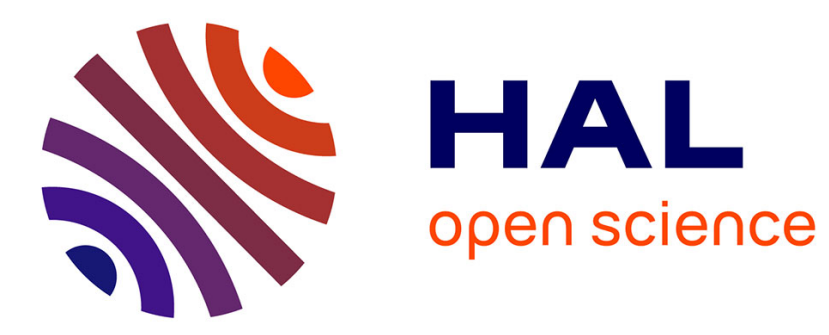

\title{
Le chantage à la guerre
}

Marie Mendras

\section{To cite this version:}

Marie Mendras. Le chantage à la guerre. Revue Esprit, 2021, 2021/6 (475), pp.28-32. 10.3917/espri.2106.0028 . hal-03509238

\section{HAL Id: hal-03509238 \\ https: / hal-sciencespo.archives-ouvertes.fr/hal-03509238}

Submitted on 4 Jan 2022

HAL is a multi-disciplinary open access archive for the deposit and dissemination of scientific research documents, whether they are published or not. The documents may come from teaching and research institutions in France or abroad, or from public or private research centers.
L'archive ouverte pluridisciplinaire HAL, est destinée au dépôt et à la diffusion de documents scientifiques de niveau recherche, publiés ou non, émanant des établissements d'enseignement et de recherche français ou étrangers, des laboratoires publics ou privés.

\section{(ㅇ)(1) 80}

Distributed under a Creative Commons Attribution - NonCommercial - ShareAlikel 4.0 


\title{
Le chantage à la guerre
}

\author{
Marie Mendras, Sciences Po, CNRS, CERI \\ In : Revue Esprit, 2021/6, p. 28-32. \\ DOI : $10.3917 /$ espri.2106.0028
}

Comment interpréter la tactique guerrière de Vladimir Poutine contre l'Ukraine au printemps 2021 ? En mars, les troupes russes, lourdement armées, se massent à la frontière ukrainienne, plus précisément le long de la frontière des régions de Lugansk et Donetsk, dont la partie orientale est occupée par des "séparatistes » soutenus et financés par Moscou depuis sept ans. Le Kremlin justifie cette « préparation militaire » par la stratégie agressive des ÉtatsUnis qui mettent en danger la sécurité de la Russie. Le 22 avril, le ministre de la Défense annonce la fin des « exercices », qui n'ont jamais été des préparatifs à une offensive russe, affirme-t-il. Menacer d'une guerre qu'on ne fera pas, telle a été la tactique du Kremlin.

\section{Sur le pied de guerre}

En janvier 2021, le pouvoir russe a intensifié son soutien aux « administrations » et groupes armés du Donbass. Les incidents graves se sont multipliés sur la ligne de front, faisant des dizaines de victimes. En avril, plus de cent mille troupes russes ont été tenues en alerte maximale à la frontière.

Le premier objectif était clairement d'exercer une forte pression sur le président Zelensky et sur les pays occidentaux, dans l'espoir de « replacer » Moscou au centre de la sécurité européenne ${ }^{1}$, et de faire diversion en reléguant au second plan la mauvaise gestion de l'épidémie de Covid, et la désastreuse affaire Navalny. Le Kremlin appliquait une tactique bien connue : menacer de faire la guerre, et jouer sur les anxiétés des peuples et de leurs dirigeants. Une forme de populisme à l'envers, où le peuple est censé s'aplatir devant la menace de chars et de bombes « ennemies ", menace brandie tous les jours dans les médias russes, et trop souvent relayée par des médias occidentaux sans analyse contradictoire.

Vladimir Poutine exacerbe la menace d'une guerre ouverte en Ukraine car l'Ukraine, c'est déjà l'Europe. Il tente une nouvelle fois de séparer l'Ukraine de ses voisins occidentaux pour l'enfermer dans une zone grise, un sanctuaire privé de souveraineté et d'identité, coincé entre la Russie et les démocraties européennes. Cet assourdissant bruit de bottes lui a permis de repousser encore les perspectives d'une sortie du conflit du Donbass. Il préfère garder au chaud un conflit qui mijote.

Il a misé sur la réticence des Européens face à l'engagement militaire pour les détacher de l'Ukraine, et aussi de la Biélorussie, de la Géorgie, de l'Arménie. À l'automne 2020, Moscou a laissé l'Azerbaïdjan et la Turquie remporter une victoire éclair contre les Arméniens du HautKarabakh, sans porter assistance à l'État arménien, son allié. La non-intervention constitue aussi une méthode russe pour affaiblir une ancienne République soviétique. Dans les deux cas, ukrainien et arménien, Vladimir Poutine a fait un calcul de court terme, car il a aiguisé la défiance de tous ses voisins pour longtemps. Plus aucun gouvernement européen n'imagine s'appuyer sur Moscou pour assurer la sécurité de l'Europe. Et la nouvelle administration Biden rejoint ses alliés sur ce constat. Le président américain est décidé à échanger avec son 
homologue russe en position de force. Il a proposé un sommet bilatéral en juin 2021, offrant ainsi à Vladimir Poutine un petit bonus de reconnaissance.

La « panique à la guerre » de mars-avril 2021 est le paroxysme d'une année très troublée. Rien n’a fonctionné comme prévu dans le calendrier poutinien. La violation du régime constitutionnel russe au printemps 2020, pour figer Poutine en président à vie (il pourrait prétendre à deux mandats supplémentaires), a contribué au durcissement de la protestation à travers la Russie. En Biélorussie, la grande majorité des électeurs se sont mobilisés contre un sixième mandat d'Alexandre Loukachenko à l'été 2020, et la révolte populaire se poursuit, en dépit d'une terrible répression².

Dans le même temps, les deux autocrates se sont révélés incapables de gérer l'épidémie de Covid-19, laissant aux administrations régionales et aux hôpitaux démunis la lourde charge de freiner la contagion et de soigner les malades. En Russie, la pandémie a causé une surmortalité de 460000 personnes, alors que les autorités recensent moins de 120000 décès dus à la Covid-19 en mai 2021. L'économie russe est exsangue, la pauvreté augmente, le mécontentement s'étend. Les élections législatives prévues en septembre 2021 inquiètent le Kremlin qui se déchaîne dans une répression violente contre tous les citoyens engagés. L'empoisonnement raté d'Alexeï Navalny et son emprisonnement dans des conditions intolérables, après une condamnation inique, ont marqué un point de non-retour. Pour survivre, le système Poutine a recours à des méthodes criminelles.

\section{La tactique de Poutine}

La défense poutinienne est de frapper en niant avoir frappé : Alexeï Navalny n'a pas été empoisonné, il n'y a jamais eu de forces russes dans le Donbass, les opposants arrêtés sont des " extrémistes ", voire des « terroristes ". Poutine n'a aucun intérêt à envahir l'Ukraine avec ses propres troupes, armements et drapeau, alors que pendant sept ans il a nié la présence militaire russe au Donbass. En 2014, les « petits hommes verts » surarmés ne portaient pas d'insigne, et les véhicules blindés roulaient en Ukraine sans plaque d'immatriculation.

Le Kremlin n'admettra jamais qu'il mène une guerre contre l'État ukrainien, et ne révisera pas son récit officiel selon lequel l'Ukraine est ravagée par une « guerre civile» entre « russophones » et « régime fasciste à Kiev », soutenu par la CIA et l'Otan. Le président, ancien patron du FSB, ne peut pas reconnaître la Spetsoperatsiia de 2014. En effet, l'annexion militaire de la Crimée et l'intervention dans le Donbass ont été menées comme des « opérations spéciales ", caractéristiques des méthodes subversives des organes de renseignement (FSB et renseignement militaire). À partir de 2014, la subversion multiforme sera la méthode principale dans la confrontation avec les « ennemis » ukrainiens, européens, américains, et bien sûr la « cinquième colonne », l'opposition russe.

La cible de la violence politique et militaire en Ukraine n'est pas l'État-territoire, mais les populations pour toucher à travers elles les dirigeants à Kiev. En Russie même, la cible est aussi la société dans son ensemble, au-delà des opposants qui la réveillent.

La « panique à la guerre » n'a pas marché, et ne marcherait sans doute pas une seconde fois. Cela ne signifie pas que Poutine soit moins dangereux. Au sein du cercle dirigeant, qui se 
met en scène comme " assiégé », s'exaspèrent les passions négatives et les raisonnements fallacieux. Une politique subversive, animée par la revanche et la peur de l'anéantissement, peut se révéler tout aussi ravageuse qu'une guerre, pour celui qui la mène comme pour ceux qui la subissent.

Vladimir Poutine a peur de la chute, et cherche à remplir le vide qu'il a créé autour de lui et autour de la Russie. Il revendique une "sphère d'influence " qu'il a perdue à force de la contraindre. Il accuse les Occidentaux et se les met à dos, alors qu'il a tant voulu les séduire et les impressionner. Il menace de faire alliance avec Xi Jinping, dont l'étreinte l'étoufferait assurément.

Poutine ne peut ni ne veut occuper l'Ukraine. Il veut mais ne peut laisser Alexeï Navalny mourir dans l'un de ses pénitenciers.

La priorité pour l'Europe est de garder la tête froide et l'esprit aguerri : vigilance absolue, solidarité forte, démontage du discours guerrier, analyse des réelles capacités de l'adversaire, sanctions ciblées, moratoire sur la mise en service du gazoduc Nord Stream 2, soutien aux pays soumis aux pressions économiques et militaires de la Russie. La sécurité des Ukrainiens, Biélorusses, Moldaves, Arméniens, Géorgiens, comme la sécurité des Russes, exige l'État de droit, le dynamisme économique, et la paix. Leur sécurité est la sécurité de l'Europe.

\section{Notes}

1.Voir Dumitru Minzarari, "The Russian military escalation around Ukraine's Donbas: Risks and scenarios for a revised EU policy », SWP Comment, no 27, avril 2021.

2.Voir Marie Mendras, «Vote populaire par temps d'épidémie », Esprit, septembre 2020 ; Laurent Germain, « Le légalisme de la société biélorusse », Esprit, octobre 2020. 